\title{
BMI open \\ A randomised controlled trial of hospital-based case management to improve colorectal cancer patients' health-related quality of life and evaluations of care
}

\author{
Christian Nielsen Wulff, ${ }^{1,2}$ Peter Vedsted, ${ }^{1}$ Jens Søndergaard ${ }^{3}$
}

To cite: Wulff CN, Vedsted $P$, Søndergaard J. A randomised controlled trial of hospitalbased case management to improve colorectal cancer patients' health-related quality of life and evaluations of care. BMJ Open 2012;2: e001481. doi:10.1136/ bmjopen-2012-001481

- Prepublication history and additional material for this paper are available online. To view these files please visit the journal online (http://dx.doi.org/10.1136/ bmjopen-2012-001481).

Received 29 June 2012 Accepted 27 September 2012

This final article is available for use under the terms of the Creative Commons Attribution Non-Commercial 2.0 Licence; see http://bmjopen.bmj.com

For numbered affiliations see end of article

Correspondence to Christian Nielsen Wulff; christian.wulff@alm.au.dk

\section{ABSTRACT}

Objective: To analyse the effectiveness of hospitalbased case management (CM) in terms of patientreported outcomes.

Design: Randomised controlled trial allocating participants $1: 1$ to either a CM intervention or a control group. Allocation status was evident to participants and case managers, but blinded to researchers.

Setting: Patients were recruited at a Danish surgical department where the case managers were situated.

Participants: Colorectal cancer patients who were to undergo further investigation or treatment. Exclusion criteria were participation in another study, poor Danish language skills or apparent cognitive impairment. 140 participants were randomised to each group. Recruitment period was 11 March 2009 to 29 December 2010.

Interventions: Control group patients had usual care. Intervention group patients had usual care supplemented by hospital-based CM started at first visit to the outpatient clinic (before treatment start) and ended 4 weeks after completed cancer treatment. CM was conducted by nurse case managers who undertook care pathway supervision, information dissemination to health professionals and outreaching patient support.

Outcome measures: Patient-reported global quality of life measured with the EORTC QLQ-C30 and eight ad hoc, piloted patient evaluation items assessed at eight, 30 and 52 weeks after randomisation.

Results: The two groups were comparable as to questionnaire response rates and completed scales/items. There were no statistically significant group differences on any of the health-related quality of life subscales at eight, 30 or 52 weeks. In patient evaluations, all point estimates favoured CM at week 8 and 30; at week 52, 6 of 7 estimates favoured $\mathrm{CM}$.

Conclusions: We found no evidence that CM influenced colorectal cancer patients' health-related quality of life. Patients allocated to CM evaluated their care more positively than patients receiving usual care.

Trial registration: Clinicaltrials.gov identifier: NCT00845247.

\section{ARTICLE SUMMARY}

Article focus

- Case management (CM) models are increasingly engaged in healthcare systems to improve coordination and continuity of care. Most programmes are based on case managers who are experienced nurses engaged full-time to undertake coordination and support in relation to individual patients having complex healthcare needs.

- Danish hospital departments treating cancer patients have been committed to deploy case managers to improve coordination and continuity of care. However, scientific evidence of the effect of $\mathrm{CM}$ in this context is scarce.

- This article presents results from a randomised controlled trial (RCT) of nurse CM for colorectal cancer (CRC) patients.

\section{Key messages}

- The manual-based CM intervention was conducted by two experienced nurses with regard to CRC care, the patient perspective and the Danish healthcare system. Main CM activities were care pathway supervision and optimisation, dissemination of patient-specific information to general practitioners and other involved healthcare personnel, and outreaching patient support.

- The CM intervention did not affect patients' health-related quality of life as measured by the EORTC QLQ-C30.

- The CM intervention showed a tendency to improve patients' evaluations of care received.

Strengths and limitations of this study

- The CM intervention was manual based, pilot tested and analysed in an RCT.

- The RCT was implemented at only one department with the consequence that patients potentially were aware about the purpose of the trial and their allocation. 


\section{INTRODUCTION}

Treatment modalities for cancer evolve rapidly and cancer survival rates are rising modestly, ${ }^{1}$ but cancer patients still suffer from reduced health-related quality of life (HRQoL) due to their disease, its treatment and the effects of existential concerns. ${ }^{2}{ }^{3}$ Many cancer patients experience cancer care as episodic and incoherent as to treatment and care, information provided and relationship with health professionals. ${ }^{4-7}$ Importantly, some studies have found a positive correlation between patients' evaluations of their care and their HRQoL. ${ }^{89}$

Case management $(\mathrm{CM})$ is often recommended as a method to improve coordination and continuity of care for individual patients having complex care needs. $\mathrm{CM}$ is usually conducted by a nurse, the case manager, who is engaged solely to function as a consistent and proactive cross-disciplinary member of the healthcare team. ${ }^{10}$

CM may be an effective method to improve coordination and continuity of cancer care and to improve cancer patients' HRQoL. However, the effectiveness of $\mathrm{CM}$ in cancer care has been sparsely studied. ${ }^{11}$ In the present study, we tested the hypothesis that hospitalbased CM during the treatment period would improve colorectal cancer (CRC) patients' HRQoL and their evaluations of care.

\section{MATERIALS AND METHODS}

Study design

Randomised controlled trial (RCT) allocating CRC patients to a CM intervention group or a control group (ratio $1: 1$ ).

\section{Setting}

The Danish healthcare system is primarily tax-financed and grants Danish citizens free access to general practitioner (GP) and public hospital services. Almost all Danes $(98 \%)$ are listed with a general practice. The GP is a gatekeeper with regard to the patient's referral to specialist services and functions as a key healthcare coordinator outside the hospitals. ${ }^{12}$

The Surgical Department P, Aarhus University Hospital, Denmark, treats all categories of CRC patients, including those who suffer from locally advanced or recurrent disease.

\section{Participants}

During the inclusion period from 11 March 2009 to 29 December 2010, all patients at Department P were assessed for inclusion. We included patients with a diagnosis of CRC or 'a highly probable diagnosis of CRC' who were to undergo further investigation or treatment at Department P. Exclusion criteria were participation in another study (see the Discussion section), poor Danish language skills or apparent cognitive dysfunction.
Interventions

Control: usual care

Control group patients were treated and cared for as usual. No designated health professional overlooked the coordination of health services for this group and they did not receive telephone calls to systematically assess their well-being and the coordination and continuity of their care. In accordance with a paragraph in the Danish Health Act, ${ }^{13}$ all control group patients were given the name and a phone number on an employee at Department $\mathrm{P}$ to grant them easy access to the department during the treatment period.

\section{CM intervention}

The main aims of the CM intervention, which was conducted supplementary to usual care, were to streamline individual patients' care pathways and improve their well-being and experiences of care. Two experienced nurses were employed from January 2009 to May 2011 to work principally as case managers. They initially went through 2 months of combined additional training and pilot testing of the manual-based CM intervention and its appertaining checklists. The case managers had their office at Department P, worked daytime and weekdays only, were introduced as members of the multidisciplinary team (MDT) and they attended all MDT meetings where most patients had their cancer staged and treatment options discussed.

A detailed manual, which was pilot tested before the trial, chronologically described the case managers' duties. As soon as possible after randomisation, the case manager scheduled a meeting with the patient to provide detailed information about the CM services and availability. In addition, the case manager made a formal assessment of the patient's medical and non-medical condition, his or her expectations regarding care, and his or her knowledge about the disease and care. An ad hoc developed needs assessment checklist was used to guide the conversation.

Throughout the period of treatment, the case manager regularly ( every fortnight) telephoned the patient to assess his or her biopsychosocial status and screen for barriers to optimal care related to coordination and awareness of the care plan. Potential inadequacies were addressed by involving relevant health professionals and by increasing the frequency of outreach telephone calls.

Patient-specific information was passed on to the GP and other relevant health professionals initially and at transitions between care settings.

Most patients met the case manager at their first meeting in the outpatient clinic which took place a few days after the patient's primary colonoscopy or for patients referred from another CRC specialist to Department $\mathrm{P}$ at the patient's first encounter in the Department. The duration of active CM varied between patients but did not terminate before 4 weeks after the patient had completed planned CRC treatment. There 
was no formal time at which patients could no longer exercise their option to contact the case manager by telephone.

Online supplementary figure S1 provides an overview of the CM intervention and the usual care in a Pat plot (figure 1). ${ }^{14}$ The $\mathrm{CM}$ intervention was pragmatically designed and operationalised the case manager's function as described in the Danish Generic Model for Care Pathway Programmes. ${ }^{15}$ The CM intervention and the methods and feasibility of the trial have been described in detail elsewhere (paper submitted to BMC Health Services Research 9 December 2011).
Outcome measures

HRQoL was assessed with the use of the Danish version of the European Organisation for Research and Treatment of Cancer Core Quality of Life Questionnaire V.3.0 (EORTC QLQ-C30), which is a validated, cancerspecific, 30-item questionnaire measuring HRQoL on: one global health status scale, five functioning scales and nine symptom scales. ${ }^{16} 17$ The primary endpoint of this study was the global health status scale. The secondary endpoints were scores on the functioning scales: physical, role, cognitive, emotional and social functioning.

\begin{tabular}{|c|c|c|}
\hline \multirow[t]{2}{*}{ Time 0} & \multicolumn{2}{|c|}{$\begin{array}{l}\text { Consecutive colorectal cancer patients at Department } P \text {, Aarhus University Hospital were } \\
\text { assessed according to inclusion and exclusion criteria. Patients who met the criteria were } \\
\text { informed about the project. Patients who returned the statement of consent and the } \\
\text { baseline questionnaire were randomized. }\end{array}$} \\
\hline & CM GROUP* & CONTROL GROUP \\
\hline Time 0 & b & e \\
\hline Week 0-8 & C & \\
\hline Week 8 & \multicolumn{2}{|c|}{ HRQoL and patient evaluation questionnaire } \\
\hline Week 9-30 & c & \\
\hline Week 30 & \multicolumn{2}{|c|}{ HRQoL and patient evaluation questionnaire } \\
\hline Week 31-52 & C & \\
\hline Week 52 & \multicolumn{2}{|c|}{ HRQoL and patient evaluation questionnaire } \\
\hline
\end{tabular}

\section{Explanations:}

\begin{tabular}{|c|c|}
\hline a & $\begin{array}{l}\text { First contact between the case manager and the patient: Information about CM } \\
\text { service and needs assessment. }\end{array}$ \\
\hline b & $\begin{array}{l}\text { Electronic letter from the case manager to the patient's GP and other relevant } \\
\text { persons: Information about CM, planned treatment and care, needs assessment and } \\
\text { shared care. }\end{array}$ \\
\hline C & $\begin{array}{l}\text { The case manager met the patient in Department } P \text { and regularly contacted the } \\
\text { patient by phone to assess bio-psycho-social well-being and information level } \\
\text { (outreach contacts ended four weeks after the end of cancer treatment). }\end{array}$ \\
\hline d & $\begin{array}{l}\text { Change in care setting and/ or treatment plan: Electronic letter from the case } \\
\text { manager to the GP and, if relevant, to other involved health care profesisionals. }\end{array}$ \\
\hline e & Information about the statutory contact person (handover of calling card). \\
\hline & Diagnosing and treatment of colorectal cancer. \\
\hline$*$ & Only planned CM activities are illustrated. In-going calls, etc. are not depicted. \\
\hline GP & General practitioner \\
\hline $\mathrm{CM}$ & Case management \\
\hline HRQoL & Health-related quality of life \\
\hline
\end{tabular}

Figure 1 Overview of the interventions. 
EORTC QLQ-C30 scores were calculated according to the scoring manual. ${ }^{18}$ Thus, a continuous scale score ranging from 0 to 100 was calculated if the patient had answered at least half of the items of the scale. A score of 100 indicated the highest functioning. For interpretation of EORTC QLQ-C30 results we set 10 units as the minimally relevant scale contrast regardless of the subscale. ${ }^{19} 20$

Eight ad hoc items from a piloted questionnaire were pre hoc selected as the primary patient-evaluation endpoints (see table 3). Six items meant to determine information and support from health professionals and continuity of care were answered using the following response categories: 'Completely agree', 'Agree', 'Do not agree', 'Completely disagree' and 'Do not know/ Not applicable'. Two items asked the patients to assess the quality of care at the surgical department and in general. These items used the following response categories: 'Excellent', 'Very good', 'Good', 'Less good' and 'Bad'.

\section{FOLLOW-UP}

HRQoL and patient evaluations were assessed 8, 30 and 52 weeks after the patient's inclusion with copies of the same questionnaire that featured the EORTC QLQ-C30 items plus 64 other items. The questionnaires and the reminders to non-responders (after 3 weeks) were sent by ordinary mail. Non-response 6 weeks after the time of the initial follow-up questionnaire prompted a reminder phone contact. HRQoL was also assessed at baseline using a questionnaire handed out at the hospital.

\section{Sample size}

Power calculations on the global health status scale revealed that we needed responses from 116 patients in each group (power of $90 \%$, two-sided significance level of $5 \%, 1: 1$ allocation) to detect 10 units of difference between groups. Due to inevitable drop-out, we aimed at including a total of 280 patients.

\section{Randomisation and allocation concealment}

The two case managers undertook recruitment in turns. After an assessment of inclusion and exclusion criteria, potential patients were informed about the trial. Those who were willing to participate were asked to fill in a consent form and the baseline questionnaire. Patients returning these documents were randomised $1: 1$ by an independent secretary using the minimisation technique $^{21}$ and the SiMin software. ${ }^{22}$ To ensure comparable groups in terms of characteristics possibly associated with the outcomes, the following stratification factors were used: gender (male/female), cancer type (rectal cancer/colon cancer) and age $(<65 / 65-79 />79$ years $)$. A random factor of $1: 4$ was used (ie, allocation included $20 \%$ randomness).

Group assignment was evident to the patients and the case managers, but was blinded to the researchers.

\section{Analyses}

Analysis of covariance (ANCOVA), which in effect adjusts each patient's follow-up score for his or her baseline score, ${ }^{23}$ was used to calculate the group difference on each of the HRQoL subscales at each time of follow-up. Analyses were accompanied by graphical presentations of the groups' mean scores stratified by the patients' last consecutive questionnaire response. These longitudinal graphical presentations served two purposes: To provide an overview of all the data at the same time; and to suggest whether any data complexity might bias the statistical analyses. ${ }^{24}$

The patient evaluation answers were dichotomised ('Completely agree' vs 'the rest' and 'Excellent' plus 'Very good' vs 'the rest'). The positive proportion of answers to each item was compared at each time of follow-up using a generalised linear model with log link for the Bernoulli family and robust variance; relative differences are presented as prevalence proportion ratios (PPRs). ${ }^{25}$

All analyses were conducted according to the 'intention-to-treat' principle, that is, patients were kept in the analyses regardless of their final diagnosis and exposure to CM (decided by duration of treatment). Statistical significance was set at $\mathrm{p} \leq 0.05$ and results should be interpreted in awareness of multiple comparisons.

To address potential attrition bias caused by uneven attrition in the two groups, ${ }^{26}$ sensitivity analyses was conducted, that is, data were analysed with adjustment for the minimisation variables and categories. We did not impute missing data because most missing data were HRQoL and patient evaluations (outcome data) from dead persons.

Primary endpoints were tested for subgroup-treatment effect interaction as to cancer type, gender and age using same categories as used in the minimisation. ${ }^{27}$ Due to the multiple testing, effect measure modification should be present at minimally two time points to be accepted as an indication of a subgroup-treatment effect.

All analyses were conducted with the use of Stata V.11.2.

\section{Ethics}

The project was ethically acceptable to both control group and intervention group patients because diagnostics and treatment were unaffected, and we did not know whether CM was superior to usual care. According to the Danish Research Ethics Committee System, ${ }^{28}$ the trial was not a biomedical intervention and did not need the ethics committee's approval. This was confirmed by correspondence with the chair of the regional ethics committee. The Danish Data Protection Agency approved the research database (J.nr. 2008-41-2932). The RCT was indexed at www.clinicaltrials.gov (ID number: NCT00845247). 


\section{RESULTS}

\section{Flow of participants}

We assessed 532 patients for inclusion and included 280 patients. Online supplementary figure S2 shows the reasons for non-participation and the group-wise flow of patients (figure 2). Table 1 shows that the patients in the two groups were similar as to age, gender, disease characteristics and self-reported variables at baseline. The CM group had marginally higher mean baseline HRQoL scores than the control group, except for cognitive functioning.

Online supplementary figure S2 shows similar response rates in the two groups at 8,30 and 52 weeks. Attrition occurred during the trial. Mortality 52 weeks after inclusion was higher in the CM group (31 patients) than in the control group (20 patients), but this difference was not statistically significant and the two groups appeared almost similar in terms of the remaining patients' characteristics (not shown). Importantly, no clinically significant differences between the unadjusted and the adjusted estimates appeared.

\section{HRQol}

Table 2 presents the EORTC QLQ-C30 mean baseline and follow-up scores at each time of follow-up and the ANCOVA-calculated differences between the two groups. No statistically significant difference between groups appeared on any subscale at any time point.

Online supplementary figure S3 offers a visual representation of the EORTC QLQ-C30 scale scores by group

Patients with a diagnosis or a 'highly-probable diagnosis' of colorectal cancer at Department P (11 March 2009 - 29 December 2010)

$\mathrm{N}=532$

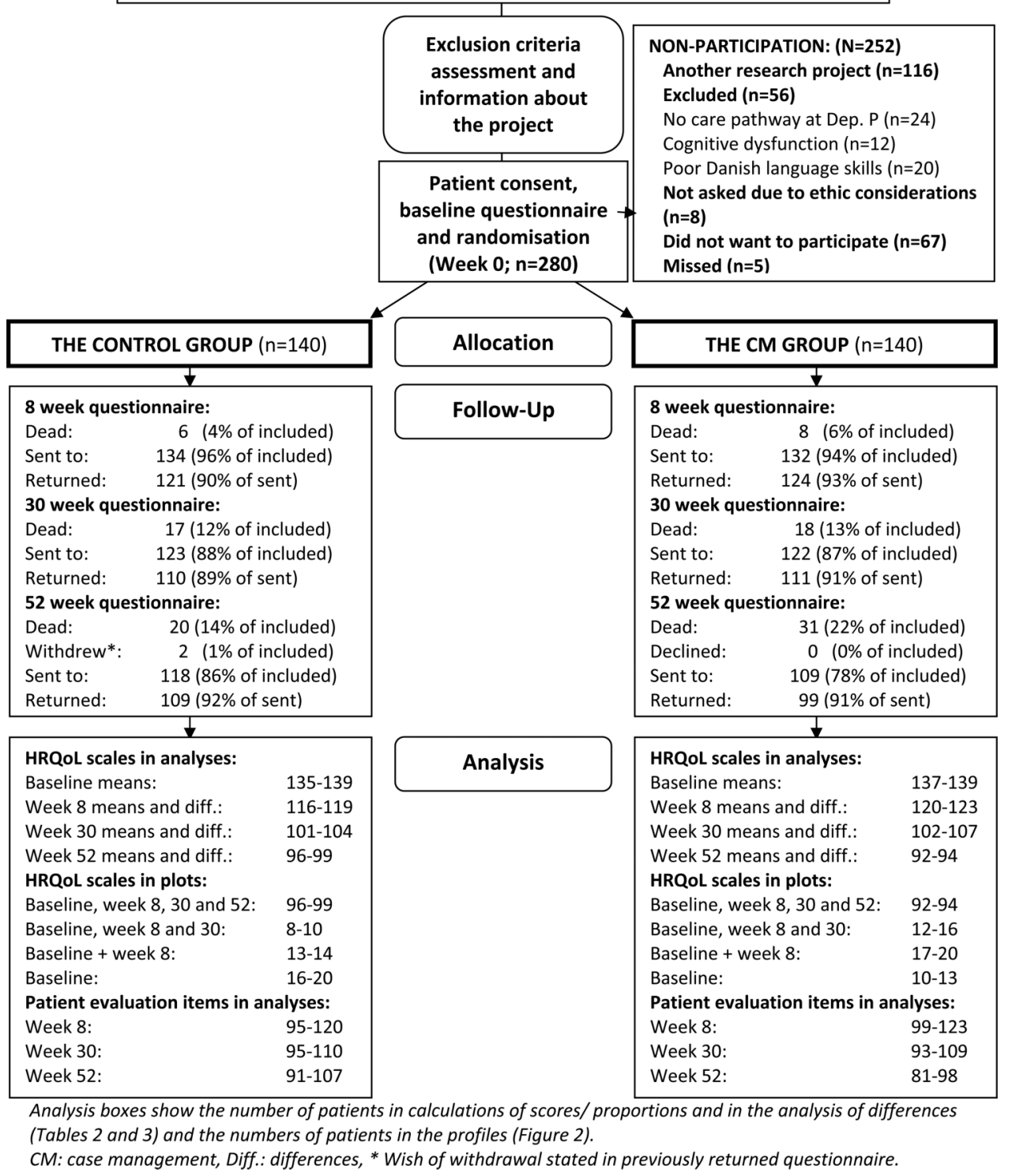

Figure 2 Trial profile 
Table 1 Participants' characteristics

\begin{tabular}{|c|c|c|}
\hline Variable & $\begin{array}{l}\text { Control group } \\
\mathrm{N}=140\end{array}$ & $\begin{array}{l}\text { CM group } \\
N=140\end{array}$ \\
\hline Mean age (SD) & $66.2(11.7)$ & $66.3(11.1)$ \\
\hline \multicolumn{3}{|l|}{ Gender } \\
\hline Female & $47(33.6 \%)$ & $47(33.6 \%)$ \\
\hline Male & $93(66.4 \%)$ & $93(66.4 \%)$ \\
\hline \multicolumn{3}{|l|}{ Disease ${ }^{\star}$} \\
\hline Colon cancer & $72(51.4 \%)$ & $70(50.0 \%)$ \\
\hline Primary & 62 & 58 \\
\hline Recurrent & 10 & 12 \\
\hline Rectal cancer & $64(45.7 \%)$ & $66(47.1 \%)$ \\
\hline Primary & 47 & 48 \\
\hline Recurrent & 17 & 18 \\
\hline Other cancert & $2(1.4 \%)$ & $2(1.4 \%)$ \\
\hline Not cancer† & $2(1.4 \%)$ & $2(1.4 \%)$ \\
\hline \multicolumn{3}{|l|}{ Surgery* } \\
\hline No & $16(11.4 \%)$ & $17(12.1 \%)$ \\
\hline Yes & $124(88.6 \%)$ & $123(87.9 \%)$ \\
\hline Endoscopic surgery & 10 & 5 \\
\hline Laparoscopic surgery & 20 & 24 \\
\hline Laparotomy & 94 & 94 \\
\hline One or more chronic disease $\ddagger$ & $73(52.1 \%)$ & $74(52.9 \%)$ \\
\hline Negative self-rated health status prior to current disease $\neq$ & $8(5.8 \%)$ & $11(8.0 \%)$ \\
\hline Living in partnership or married $\ddagger$ & $99(72.3 \%)$ & $103(73.6 \%)$ \\
\hline Income $<33.500$ EUR/year $\ddagger$ & $56(41.2 \%)$ & $51(37.0 \%)$ \\
\hline Without a job (senior citizen, unemployed etc.) $\ddagger$ & $90(67.2 \%)$ & $93(67.9 \%)$ \\
\hline \multicolumn{3}{|l|}{ EORTC QLQ-C30‡ } \\
\hline Global quality of life & $59.36(25.54)$ & $62.41(22.96)$ \\
\hline Physical functioning & $80.96(21.12)$ & 83.39 (19.47) \\
\hline Role functioning & 67.78 (34.87) & 69.71 (34.49) \\
\hline Emotional functioning & $71.88(23.31)$ & $72.56(23.13)$ \\
\hline Cognitive functioning & $86.47(16.55)$ & $85.27(21.13)$ \\
\hline Social functioning & 81.27 (24.95) & 83.58 (22.51) \\
\hline \multicolumn{3}{|c|}{$\begin{array}{l}\text { Data are means (SD) or numbers (\%). } \\
\text { *Information found in medical records and hospital registers. } \\
\text { †Eight patients were falsely thought to suffer from colorectal cancer at the time of inclusion. } \\
\text { †Reported by patients in the baseline questionnaire. } \\
\text { CM, case management; EORTC QLQ-C30, the European Organisation for Research and Treatment of } \\
\text { Cancer Core Quality of Life Questionnaire V.3.0 }\end{array}$} \\
\hline
\end{tabular}

and over time. Seventy-one per cent of all participants (103 control group patients and 95 CM patients) answered the baseline questionnaire and all answered the three follow-up questionnaires (complete follow-up; black markers and lines). Online supplementary figure S3 shows that non-random drop-out applied to most scales, that is, the non-responder group had statistically significantly lower scores at the assessment prior to nonresponse than the responder group. The mean scores of the two subgroups characterised by complete follow-up appeared not to differ, and the profiles of the mean scores changed similarly over time. The partial follow-up profiles appeared less uniform, but plots were based on a maximum of 20 responses per group (figure 3).

\section{Patient evaluation of care}

Table 3 shows the dichotomised patient evaluations at week 8,30 and 52. The two groups were almost identical as to numbers of 'Don't know/ Not applicable' answers and skipped items so these 'responses' were omitted from analyses. The PPRs of 23 of 24 items favoured the CM group. Five, three and zero items differed statistically significant at week 8,30 and 52, respectively.

We found no statistically significant subgrouptreatment effect interaction as to the global quality of life-scale or the patient evaluation items.

\section{DISCUSSION}

\section{Statement of principal findings}

We found no effect of a manual-based CM intervention on patients' global health status or their functioning as assessed from the EORTC QLQ-C30 questionnaire. Patients of the CM group answered almost all (23 of 24) patient evaluation items more positively than the control group patients. The items regarding 'the experience of being continuously followed by a doctor or a nurse', and 
Table 2 Mean baseline and mean follow-up scale scores and ANCOVA-calculated group differences

\begin{tabular}{|c|c|c|c|c|c|c|c|c|c|}
\hline & \multicolumn{3}{|c|}{8 weeks (if baseline scale) } & \multicolumn{3}{|c|}{30 weeks (if baseline and 8 weeks scale) } & \multicolumn{3}{|c|}{52 weeks (if baseline, 8 and 30 weeks scale) } \\
\hline & \multicolumn{3}{|c|}{ n-Control group: 116-119 } & \multicolumn{3}{|c|}{ n-Control group: 101-104 } & \multicolumn{3}{|c|}{ n-Control group: 96-99 } \\
\hline & \multicolumn{3}{|c|}{ n-CM group: 120-123 } & \multicolumn{3}{|c|}{ n-CM group: 102-107 } & \multicolumn{3}{|c|}{ n-CM group: 92-94 } \\
\hline & $\begin{array}{l}\text { Baseline } \\
\text { Mean (SD) }\end{array}$ & $\begin{array}{l}\text { Follow-up } \\
\text { Mean (SD) }\end{array}$ & $\begin{array}{l}\text { Group difference } \\
(95 \% \mathrm{Cl})\end{array}$ & $\begin{array}{l}\text { Baseline } \\
\text { Mean (SD) }\end{array}$ & $\begin{array}{l}\text { Follow-up } \\
\text { Mean (SD) }\end{array}$ & $\begin{array}{l}\text { Group difference } \\
(95 \% \mathrm{Cl})\end{array}$ & $\begin{array}{l}\text { Baseline } \\
\text { Mean (SD) }\end{array}$ & $\begin{array}{l}\text { Follow-up } \\
\text { Mean (SD) }\end{array}$ & $\begin{array}{l}\text { Group difference } \\
(95 \% \mathrm{Cl})\end{array}$ \\
\hline \multicolumn{10}{|c|}{ Global quality of life } \\
\hline Control group & $61.02(25.90)$ & $61.58(21.43)$ & $1.34(-3.41$ to 6.08$)$ & $64.90(23.68)$ & $71.15(20.57)$ & $-0.91(-5.91$ to 4.09$)$ & $65.73(22.19)$ & $74.06(21.17)$ & $-4.16(-10.38$ to 2.06$)$ \\
\hline CM group & $64.58(22.04)$ & $64.38(20.41)$ & $\mathrm{p}=0.579$ & $66.09(21.02)$ & $71.24(21.58)$ & $\mathrm{p}=0.720$ & $67.21(21.07)$ & $70.56(26.07)$ & $\mathrm{p}=0.189$ \\
\hline \multicolumn{10}{|c|}{ Physical functioning } \\
\hline Control group & $84.16(18.54)$ & $73.69(23.17)$ & $0.27(-4.65$ to 5.18$)$ & $85.69(17.05)$ & $80.49(21.52)$ & $-3.42(-8.17$ to 1.33$)$ & $86.53(15.96)$ & $83.90(19.30)$ & $-2.04(-6.46$ to 2.38$)$ \\
\hline CM group & $84.88(18.45)$ & $74.40(21.63)$ & $\mathrm{p}=0.915$ & $86.29(16.09)$ & $78.08(22.03)$ & $p=0.157$ & $86.03(16.30)$ & $81.49(19.68)$ & $\mathrm{p}=0.363$ \\
\hline \multicolumn{10}{|l|}{ Role functioning } \\
\hline Control group & 70.26 (32.95) & $53.30(35.11)$ & $1.91(-6.47$ to 10.29$)$ & $73.10(31.36)$ & $72.94(31.34)$ & $-3.19(-10.46$ to 4.08$)$ & $74.48(30.10)$ & $80.03(28.78)$ & $-2.29(-9.97$ to 5.40$)$ \\
\hline CM group & $71.14(33.61)$ & $55.56(35.37)$ & $\mathrm{p}=0.654$ & 74.37 (31.22) & $71.23(29.68)$ & $\mathrm{p}=0.388$ & $75.81(31.04)$ & $78.14(27.47)$ & $\mathrm{p}=0.558$ \\
\hline \multicolumn{10}{|c|}{ Emotional functioning } \\
\hline Control group & $73.00(23.13)$ & $76.18(22.91)$ & $3.35(-1.41$ to 8.11$)$ & $74.87(21.69)$ & $85.36(18.94)$ & $-4.19(-8.75$ to 0.36$)$ & $75.62(21.23)$ & $86.22(19.22)$ & $-2.08(-7.56$ to 3.40$)$ \\
\hline CM group & $73.75(22.43)$ & $79.94(22.13)$ & $\mathrm{p}=0.167$ & $75.05(20.65)$ & $82.34(20.94)$ & $\mathrm{p}=0.071$ & $75.27(20.68)$ & $84.04(21.01)$ & $\mathrm{p}=0.455$ \\
\hline \multicolumn{10}{|c|}{ Cognitive functioning } \\
\hline Control group & $87.11(16.73)$ & $85.29(19.55)$ & $0.14(-4.28$ to 4.55$)$ & $88.46(15.93)$ & $85.42(17.64)$ & $-0.36(-4.47$ to 3.76$)$ & $89.06(15.09)$ & $88.22(15.84)$ & $-0.78(-4.95$ to 3.38$)$ \\
\hline CM group & $87.98(18.34)$ & $85.93(20.67)$ & $\mathrm{p}=0.952$ & 88.84 (16.38) & 85.38 (18.36) & $\mathrm{p}=0.864$ & $89.36(15.81)$ & $87.59(17.44)$ & $\mathrm{p}=0.711$ \\
\hline \multicolumn{10}{|c|}{ Social functioning } \\
\hline Control group & 83.05 (23.77) & 73.31 (25.89) & $2.34(-3.43$ to 8.12$)$ & $85.92(20.71)$ & $83.17(23.40)$ & $-2.86(-8.24$ to 2.52$)$ & $86.73(20.30)$ & 86.39 (22.49) & $-1.06(-7.02$ to 4.90$)$ \\
\hline CM group & $84.44(22.44)$ & 76.45 (26.59) & $\mathrm{p}=0.425$ & $86.19(20.21)$ & $82.22(23.14)$ & $\mathrm{p}=0.295$ & $87.10(20.43)$ & $85.48(22.42)$ & $\mathrm{p}=0.726$ \\
\hline
\end{tabular}


Figure 3 Average EORTC QLQ-C30 scale scores by group and by length of follow-up.
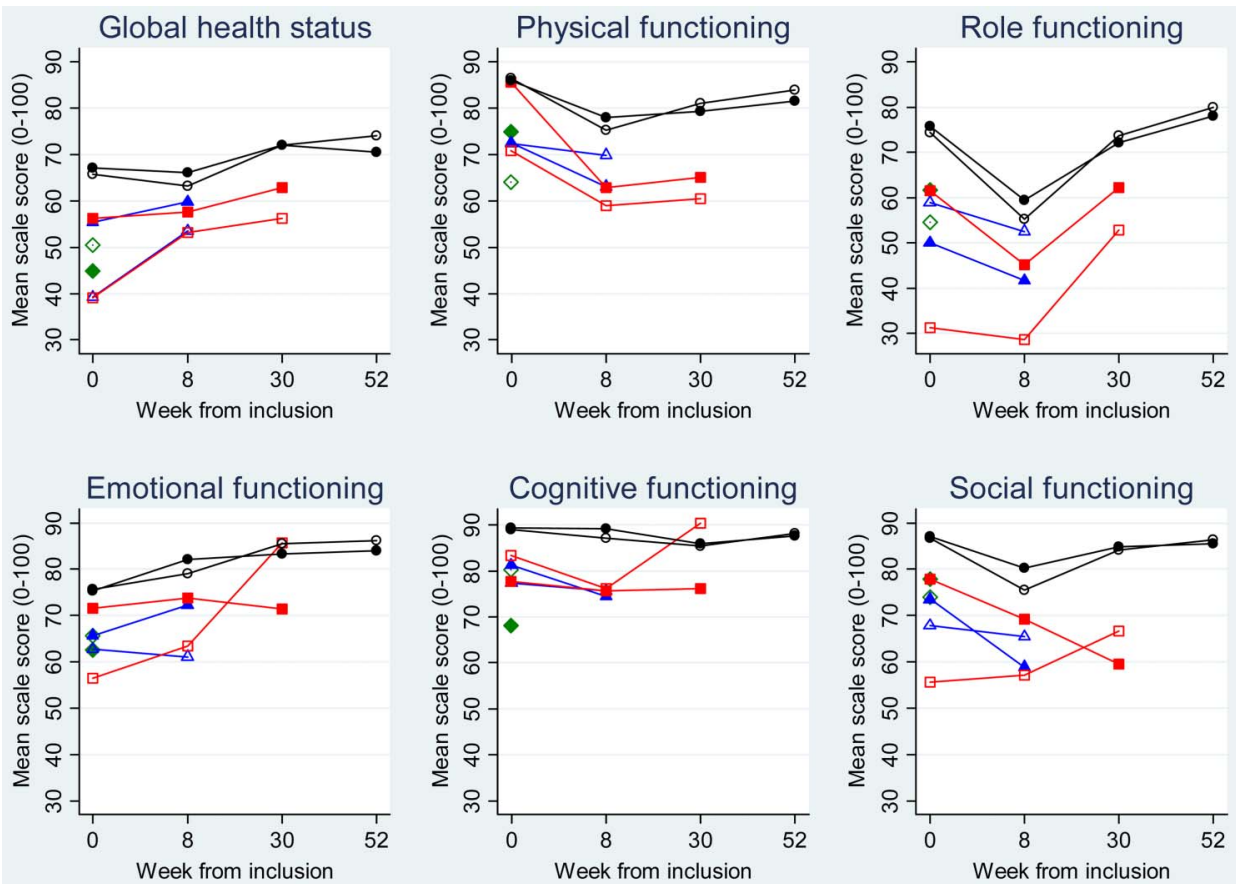

'confident about going home after surgery' seemed, in particular, to be more positively evaluated by CM patients than by the control group. We found no statistical indication that any subgroup (gender, age or cancer type) benefited differently from CM.

\section{Strengths and weaknesses}

The principal strength of this study was the comprehensive, manual-based CM intervention performed in the RCT design. A statement of the case managers' activities from the CM records and a debriefing of the case managers indicated that the CM intervention was conducted according to the manual (reported in a paper submitted to another journal).

Another strength was the use of the EORTC QLQ-C30, which is the most used validated HRQoL instruments in CRC settings and available in Danish. EORTC QLQ-C30 focuses on domains relevant to most cancer patients and minimally clinically relevant crosssectional contrasts have been proposed to guide the interpretation of findings. ${ }^{19}$ In this study, all the confidence limits of the difference estimates were within \pm 10 units (after round off). We are therefore convinced that we do not reject a clinically significant effect of CM.

Patient evaluations were assessed using ad hoc items which may be a potential weakness compared with instruments with established measurement properties and 'benchmark scores'. The use of ad hoc items was deemed necessary because existing relevant measures were found to focus on either the inpatient or the outpatient setting and not on care across care interfaces. We argue that it is acceptable to analyse non-validated items in a trial as long as items are presented by their exact wording and analyses are conducted item by item.

This RCT was implemented with randomisation at the patient level and with both patient groups being treated at the same department at the same time. We acknowledge that an intervention based on visibility and communication would have been more validly tested in a cluster-randomised trial with randomisation performed at department or hospital level. Anyway, the success of a cluster randomised trial relies on its inclusion of several treatment units which was hindered by our budget. ${ }^{29}$ The two main limitations caused by the single unit set-up were: (1) patient evaluations might have suffered from information bias because patients had information about the purpose of the trial and they were unblinded to group assignment. To reduce information bias caused by patients' experience of 'losing' or 'winning' the randomisation procedure, patients were neutrally informed about the purpose of the trial at recruitment. In addition, we believe patients over time 'forgot' about taking part in a randomised study for which reason the patient evaluations were unaffected by information bias. (2) The usual staff noticed 'effective' CM actions which they tried to 'copy' to improve control group patients' care (spill-over effect). It is very unlikely that control group patients had ongoing support and supervision, because this would require organisational restructuring (eg, revised work plans) or extra manpower, which did not take place.

A known problem when assessing patient-reported outcomes is missing data and, as for HRQoL-data, nonrandom dropout ${ }^{24}$ due to deaths. Importantly, although more CM patients than control group patients were dead at 52 weeks, online supplementary figure S3 does 
Table 3 Numbers and proportions () of patients taking a very positive or less positive stand, and the group differences.

\begin{tabular}{|c|c|c|c|c|c|c|c|c|c|}
\hline \multirow[b]{3}{*}{ Patient evaluation item } & \multirow{2}{*}{\multicolumn{2}{|c|}{$\begin{array}{l}\text { Week } 8 \text { after inclusion } \\
\text { Very positive/less } \\
\text { positive }\end{array}$}} & \multirow[b]{3}{*}{$\begin{array}{l}\text { PPR } \\
(95 \% \mathrm{CI})\end{array}$} & \multirow{2}{*}{\multicolumn{2}{|c|}{$\begin{array}{l}\text { Week } 30 \text { after inclusion } \\
\text { Very positive/less } \\
\text { positive }\end{array}$}} & \multirow[b]{3}{*}{ PPR } & \multicolumn{3}{|c|}{ Week 52 after inclusion } \\
\hline & & & & & & & $\begin{array}{l}\text { Very posit } \\
\text { positive }\end{array}$ & ve/less & \multirow[b]{2}{*}{$\begin{array}{l}\text { PPR } \\
(95 \% \mathrm{Cl})\end{array}$} \\
\hline & $\begin{array}{l}\text { Usual } \\
\text { care } \\
\mathrm{N}=121\end{array}$ & $\begin{array}{l}\mathrm{CM} \\
\mathrm{N}=124\end{array}$ & & $\begin{array}{l}\text { Usual } \\
\text { care } \\
\mathrm{N}=110\end{array}$ & $\begin{array}{l}\text { CM } \\
N=111\end{array}$ & & $\begin{array}{l}\text { Usual } \\
\text { care } \\
\mathrm{N}=109\end{array}$ & $\begin{array}{l}\mathrm{CM} \\
\mathrm{N}=99\end{array}$ & \\
\hline Overall, the information was satisfactory & $\begin{array}{l}50(0.43) / \\
67(0.57)\end{array}$ & $\begin{array}{l}58(0.48) / \\
63(0.52)\end{array}$ & $\begin{array}{l}1.12 \\
(0.85 \text { to } 1.49) \\
p=0.423\end{array}$ & $\begin{array}{l}34(0.33) / \\
70(0.67)\end{array}$ & $\begin{array}{l}50(0.47) / \\
56(0.53)\end{array}$ & $\begin{array}{l}1.44 \\
(1.03 \text { to } 2.03) \\
p=0.036^{*}\end{array}$ & $\begin{array}{l}36(0.35) / \\
68(0.65)\end{array}$ & $\begin{array}{l}40(0.42) / \\
56(0.58)\end{array}$ & $\begin{array}{l}1.20 \\
(0.84 \text { to } 1.72) \\
p=0.307\end{array}$ \\
\hline $\begin{array}{l}\text { Doctors and nurses have overall been } \\
\text { good at offering my family guidance, } \\
\text { counselling, support and help. }\end{array}$ & $\begin{array}{l}35(0.36) / \\
63(0.64)\end{array}$ & $\begin{array}{l}40(0.38) / \\
64(0.62)\end{array}$ & $\begin{array}{l}1.08 \\
(0.75 \text { to } 1.55) \\
p=0.687\end{array}$ & $\begin{array}{l}28(0.29) / \\
67(0.71)\end{array}$ & $\begin{array}{l}33(0.35) / \\
60(0.65)\end{array}$ & $\begin{array}{l}1.20 \\
(0.79 \text { to } 1.82) \\
p=0.382\end{array}$ & $\begin{array}{l}30(0.33) / \\
61(0.67)\end{array}$ & $\begin{array}{l}32(0.40) / \\
49(0.60)\end{array}$ & $\begin{array}{l}1.20 \\
(0.80 \text { to } 1.79) \\
p=0.374\end{array}$ \\
\hline $\begin{array}{l}\text { At no time have I been in doubt about who } \\
\text { to contact if I needed guidance, } \\
\text { counselling, support and help }\end{array}$ & $\begin{array}{l}55(0.47) / \\
61(0.53)\end{array}$ & $\begin{array}{l}78(0.63) / \\
45(0.37)\end{array}$ & $\begin{array}{l}1.34 \\
(1.06 \text { to } 1.69) \\
p=0.015^{\star}\end{array}$ & $\begin{array}{l}54(0.50) / \\
55(0.50)\end{array}$ & $\begin{array}{l}60(57) / 46 \\
(0.43)\end{array}$ & $\begin{array}{l}1.14 \\
(0.89 \text { to } 1.47) \\
p=0.302\end{array}$ & $\begin{array}{l}45(0.43) / \\
60(0.57)\end{array}$ & $\begin{array}{l}47(0.48) / \\
50(0.52)\end{array}$ & $\begin{array}{l}1.13 \\
(0.84 \text { to } 1.53) \\
p=0.426\end{array}$ \\
\hline $\begin{array}{l}\text { In my experience, a doctor or a nurse from } \\
\text { the hospital has been there for me through } \\
\text { my entire treatment course }\end{array}$ & $\begin{array}{l}51(0.45) / \\
63(0.55)\end{array}$ & $\begin{array}{l}73(0.60) / \\
49(0.40)\end{array}$ & $\begin{array}{l}1.34 \\
(1.04 \text { to } 1.72) \\
p=0.023^{*}\end{array}$ & $\begin{array}{l}46(0.43) / \\
60(0.57)\end{array}$ & $\begin{array}{l}68(65) / 36 \\
(0.35)\end{array}$ & $\begin{array}{l}1.51 \\
(1.16 \text { to } 1.95) \\
p=0.002^{*}\end{array}$ & $\begin{array}{l}42(0.41) / \\
61(0.59)\end{array}$ & $\begin{array}{l}46(0.47) / \\
52(0.53)\end{array}$ & $\begin{array}{l}1.15 \\
(0.84 \text { to } 1.58) \\
p=0.381\end{array}$ \\
\hline $\begin{array}{l}\text { When I was discharged after surgery, I felt } \\
\text { confident about going home }\end{array}$ & $\begin{array}{l}34(0.36) / \\
61(0.64)\end{array}$ & $\begin{array}{l}53(0.54) / \\
46(0.46)\end{array}$ & $\begin{array}{l}1.50 \\
(1.08 \text { to } 2.07) \\
p=0.016^{*}\end{array}$ & $\begin{array}{l}34(0.35) / \\
63(0.65)\end{array}$ & $\begin{array}{l}49(0.49) / \\
51(0.51)\end{array}$ & $\begin{array}{l}1.40 \\
(1.00 \text { to } 1.96) \\
p=0.052^{*}\end{array}$ & $\begin{array}{l}34(0.36) / \\
61(0.64)\end{array}$ & $\begin{array}{l}43(0.48) / \\
47(0.52)\end{array}$ & $\begin{array}{l}1.33 \\
(0.95 \text { to } 1.89) \\
p=0.102^{*}\end{array}$ \\
\hline $\begin{array}{l}\text { In my experience, my treatment course } \\
\text { has been coherent }\end{array}$ & $\begin{array}{l}41(0.36) / \\
74(0.64)\end{array}$ & $\begin{array}{l}57(0.48) / \\
61(0.52)\end{array}$ & $\begin{array}{l}1.35 \\
(0.99 \text { to } 1.85) \\
p=0.054\end{array}$ & $\begin{array}{l}39(0.38) / \\
65(0.62)\end{array}$ & $\begin{array}{l}52(50) / 53 \\
(0.50)\end{array}$ & $\begin{array}{l}1.32 \\
(0.96 \text { to } 1.81) \\
p=0.084\end{array}$ & $\begin{array}{l}36(0.35) / \\
66(0.65)\end{array}$ & $\begin{array}{l}41(0.44) / \\
52(0.56)\end{array}$ & $\begin{array}{l}1.25 \\
(0.88 \text { to } 1.77) \\
p=0.212\end{array}$ \\
\hline $\begin{array}{l}\text { How do you assess the quality of your } \\
\text { investigation and treatment at Department } \\
\text { P so far? }\end{array}$ & $\begin{array}{l}89(0.76) / \\
28(0.24)\end{array}$ & $\begin{array}{l}105(0.88) / \\
15(0.12)\end{array}$ & $\begin{array}{l}1.15 \\
(1.02 \text { to } 1.30) \\
p=0.025^{*}\end{array}$ & $\begin{array}{l}89(0.82) / \\
19(0.18)\end{array}$ & $\begin{array}{l}96(88) / 13 \\
(0.12)\end{array}$ & $\begin{array}{l}1.07 \\
(0.96 \text { to } 1.19) \\
p=0.242\end{array}$ & $\begin{array}{l}88(0.85) / \\
16(0.15)\end{array}$ & $\begin{array}{l}85(0.88) / \\
12(0.12)\end{array}$ & $\begin{array}{l}1.04 \\
(0.93 \text { to } 1.16) \\
p=0.537\end{array}$ \\
\hline $\begin{array}{l}\text { How do you assess the quality of your overall } \\
\text { diagnostics and treatment so far? }\end{array}$ & $\begin{array}{l}85(0.71) / \\
35(0.29)\end{array}$ & $\begin{array}{l}95(0.77) / \\
28(0.23)\end{array}$ & $\begin{array}{l}1.09 \\
(0.94 \text { to } 1.27) \\
p=0.258\end{array}$ & $\begin{array}{l}77(0.70) / \\
33(0.30)\end{array}$ & $\begin{array}{l}85(78) / 24 \\
(0.22)\end{array}$ & $\begin{array}{l}1.11 \\
(0.95 \text { to } 1.30) \\
p=0.181\end{array}$ & $\begin{array}{l}75(0.70) / \\
32(0.30)\end{array}$ & $\begin{array}{l}68(0.69) / \\
30(0.31)\end{array}$ & $\begin{array}{l}0.99 \\
(0.83 \text { to } 1.19) \\
p=0.913\end{array}$ \\
\hline
\end{tabular}


not indicate that we have overlooked a positive effect of $\mathrm{CM}$ on the global health status, physical functioning or the role functioning subscales due to non-random drop-out. On the other hand, the emotional functioning, cognitive functioning and social functioning differences might have been biased favouring the control group as a consequence of excess deaths in the $\mathrm{CM}$ group. Thus, online supplementary figure S3 insinuates that the CM patients who withdrew between weeks 30 and 52 might already have experienced diminishing functioning on these scales at 30 weeks.

Although the baseline questionnaire was returned before the concealed randomisation, CM patients had higher mean baseline scores on five of the six EORTC QLQ-C30 subscales than the control group patients. Importantly, ANCOVA appropriately handles such 'by chance problem' without introducing bias. ${ }^{23}$

Despite multiple comparisons, $\mathrm{p} \leq 0.05$ was generally used as the level of statistical significance. Importantly, even if we had adjusted the $p$ values to counteract the problem of multiple comparisons we would still report the tendency towards improved patient evaluations in the CM group.

\section{Generalisability}

Non-participants and participants differed in terms of cancer type and age. The group of CM participants counted statistically more rectal cancer patients than the usual care group and they were slightly, but statistically, significantly older. The primary reason for this was that another study included patients suffering from primary non-metastatic rectal cancer, who we thus could not include.

The results can be generalised to a wider group of cancer patients, primarily for two reasons: (1) interaction analyses indicated that no particular subgroup (gender, age or cancer type) benefited from CM and (2) previous research has shown that patients suffering from different cancer types face identical psychosocial problems and healthcare system-related barriers. ${ }^{30} 31$

\section{Comparisons with other studies and meaning of the study}

The present study found that CM improved patient evaluations of care even if attrition over time reduced the power of the analyses. Improved patient evaluations have also been reported in other CM RCTs. ${ }^{32-34}$ The consistent finding of improved patient evaluations despite the use of different measures is important because patient evaluations may be seen as a quality criterion at par with 'technical quality' and objective outcomes. ${ }^{35}$ Observational and qualitative studies including CRC patients have found that patients' care evaluations correlate positively with their HRQoL. ${ }^{8}{ }^{9}$ Anyway, based on the 'neutral findings' in present and previous CM trials, ${ }^{323637}$ one may speculate whether it is possible for case managers to improve cancer patients' HRQoL during the treatment phase. One explanation may be that CM does not alleviate the impact of cancer symptoms, adverse treatment effects and the existential concerns on patients' HRQoL. Another plausible explanation is poor responsiveness of the existing HRQoL instruments in the 'new' settings they have been applied. ${ }^{38}$ Retrospectively, we regret that we did not consider including an anchor item in our questionnaire for the purpose of responsiveness analyses of the EORTC QLQ-C30 in the setting and context of present trial.

\section{Unanswered questions and future research}

This CM study focused on patient-reported outcomes. CM may also be implemented to reduce the amount of 'inappropriate' healthcare services (duplicated services, unplanned readmissions and out-of-hours services) or if it enhances information transfer and professional collaboration around the patient. Yet, these issues remain to be explored.

\section{CONCLUSIONS}

In this RCT of CRC patients undergoing treatment, we found no impact of hospital-based CM on patients' HRQoL at week 8, 30 or 52 after inclusion, but several patient evaluation items were statistically significantly improved by $\mathrm{CM}$, and a tendency towards better patient evaluations in the CM group than in the usual care group was observed.

\section{Author affiliations}

${ }^{1}$ The Research Unit for General Practice in Aarhus, Department of Public Health, Aarhus University, Aarhus C, Denmark

${ }^{2}$ Section for General Medical Practice, Department of Public Health, Aarhus University, Aarhus C, Denmark

${ }^{3}$ The Research Unit of General Practice in Odense, Institute of Public Health, University of Southern Denmark, Odense C, Denmark

Acknowledgements The authors wish to thank all patients and the staff at Surgical Department P, Aarhus University Hospital, Aarhus, Denmark and all the GPs who filled in the questionnaires. We also wish to thank IT-officer Hanne Beyer for creating research databases and statisticians Ineta Sokolowski and Morten Fenger-Grøn for discussions regarding the analyses. Also thanks to Professor Frede Olesen for assistance developing and implementing the RCT.

Contributors CNW is the guarantor of the paper, design of the study, handled the data and the statistical analysis and drafted the manuscript. JS and PV designed the study and drafted the manuscript. All authors read and approved the final manuscript.

Funding This study was funded by the Danish Cancer Society, the Novo Nordic Foundation, the Danish Council for Independent Research - Medical Sciences, and the Quality and Continuing Training Council for GPs in the Central Denmark Region.

Competing interests None.

Ethics approval The Danish Data Protection Agency approved the research database (J.nr. 2008-41-2932).

Provenance and peer review Not commissioned; externally peer reviewed. Data sharing statement There are no additional data available.

\section{REFERENCES}

1. Storm HH, Kejs AM, Engholm G, et al. Trends in the overall survival of cancer patients diagnosed 1964-2003 in the Nordic countries 
followed up to the end of 2006: the importance of case-mix. Acta Oncol 2010;49:713-24.

2. Henoch I, Danielson E. Existential concerns among patients with cancer and interventions to meet them: an integrative literature review. Psychooncology 2009;18:225-36.

3. Bottomley A. The cancer patient and quality of life. Oncologist 2002;7:120-5.

4. Fincham L, Copp G, Caldwell K, et al. Supportive care: experiences of cancer patients. Eur J Oncol Nurs 2005:9:258-68.

5. Preston C, Cheater F, Baker R, et al. Left in limbo: patients' views on care across the primary/secondary interface. Qual Health Care 1999;8:16-21.

6. Kripalani S, LeFevre F, Phillips $\mathrm{CO}$, et al. Deficits in communication and information transfer between hospital-based and primary care physicians: implications for patient safety and continuity of care. JAMA 2007;297:831-41.

7. Haggerty JL, Reid RJ, Freeman GK, et al. Continuity of care: a multidisciplinary review. BMJ 2003;327:1219-21.

8. Yost KJ, Hahn EA, Zaslavsky AM, et al. Predictors of health-related quality of life in patients with colorectal cancer. Health Qual Life Outcomes 2008;6:66.

9. Dunn J, Lynch B, Rinaldis M, et al. Dimensions of quality of life and psychosocial variables most salient to colorectal cancer patients. Psychooncology 2006;15:20-30

10. Lee DT, Mackenzie AE, Dudley-Brown S, et al. Case management: a review of the definitions and practices. J Adv Nurs 1998;27:933-9.

11. Wulff CN, Thygesen M, Sondergaard J, et al. Case management used to optimize cancer care pathways: a systematic review. BMC Health Serv Res 2008;8:227.

12. Andersen JS, Olivarius N de F, Krasnik A. The Danish National Health Service Register. Scand J Public Health 2011;39:34-7.

13. The Ministry of the Interior and Health. The Danish Health Act No 913 of 13 July 2010 (In Danish). https://www.retsinformation.dk/ forms/r0710.aspx?id=130455(accessed 15 Jan 2012).

14. Perera R, Heneghan C, Yudkin P. Graphical method for depicting randomised trials of complex interventions. BMJ 2007;334:127-9.

15. The National Board of Health. Chronic disease management: a national strategy — disease management programmes and self-management support. Copenhagen: The National Board of Health, 2007.

16. Aaronson NK, Ahmedzai S, Bergman B, et al. The European Organization for Research and Treatment of Cancer QLQ-C30: a quality-of-life instrument for use in international clinical trials in oncology. J Natl Cancer Inst 1993;85:365-76.

17. Bjordal K, de Graeff A, Fayers PM, et al. A 12 country field study of the EORTC QLQ-C30 (version 3.0) and the head and neck cancer specific module (EORTC QLQ-H\&N35) in head and neck patients. EORTC Quality of Life Group. Eur J Cancer 2000;36:1796-807.

18. Fayers PM, Aaronson NK, Bjordal K, et al. The EORTC QLQ-C3O scoring manual. 3rd edn. Brussels: The European Organization for Research and Treatment of Cancer, 2001.

19. Cocks K, King MT, Velikova G, et al. Evidence-based guidelines for determination of sample size and interpretation of the European organisation for the research and treatment of cancer quality of life questionnaire core 30. J Clin Oncol 2011;29:89-96.

20. Osoba D, Rodrigues G, Myles J, et al. Interpreting the significance of changes in health-related quality-of-life scores. $J$ Clin Oncol 1998:16:139-44.
21. Treasure T, MacRae KD. Minimisation: the platinum standard for trials? Randomisation doesn't guarantee similarity of groups; minimisation does. BMJ 1998;317:362-3.

22. Wade $\mathrm{A}, \mathrm{Pan} \mathrm{H}$, Eaton $\mathrm{S}$, et al. An investigation of minimisation criteria. BMC Med Res Methodol 2006;6:11.

23. Vickers AJ, Altman DG. Statistics notes: analysing controlled trials with baseline and follow up measurements. BMJ 2001;323:1123-4.

24. Klee M, Groenvold M, Machin D. Using data from studies of health-related quality of life to describe clinical issues examples from a longitudinal study of patients with advanced stages of cervical cancer. Qual Life Res 1999;8:733-42.

25. Barros AJ, Hirakata VN. Alternatives for logistic regression in cross-sectional studies: an empirical comparison of models that directly estimate the prevalence ratio. BMC Med Res Methodol 2003;3:21.

26. Juni P. Egger M. Commentary: empirical evidence of attrition bias in clinical trials. Int J Epidemiol 2005;34:87-8.

27. Rothwell PM. Treating individuals 2 . Subgroup analysis in randomised controlled trials: importance, indications, and interpretation. Lancet 2005;365:176-86.

28. The Ministry of the Interior and Health. Act on a biomedical research ethics committee system and the processing of biomedical research projects. Copenhagen: The Ministry of the Interior and Health, 2011. http://www.cvk.sum.dk/English/actonabiomedicalresearch.aspx (assessed 7 Jun 2012)

29. Rothman KJ. Epidemiology: an introduction. Oxford: Oxford University Press, 2002

30. Ernstmann N, Neumann M, Ommen O, et al. Determinants and implications of cancer patients' psychosocial needs. Support Care Cancer 2009:17:1417-23.

31. The Danish Cancer Society. A cancer patient's world. An investigation of what Danish cancer patients need-results, evaluations and suggestions (In Danish). Copenhagen: The Danish Cancer Society, 2006.

32. Moore S, Corner J, Haviland J, et al. Nurse led follow up and conventional medical follow up in management of patients with lung cancer: randomised trial. $B M J$ 2002;325:1145.

33. Engelhardt JB, McClive-Reed KP, Toseland RW, et al. Effects of a program for coordinated care of advanced illness on patients, surrogates, and healthcare costs: a randomized trial. Am J Manag Care 2006;12:93-100.

34. Goodwin JS, Satish S, Anderson ET, et al. Effect of nurse case management on the treatment of older women with breast cancer. $J$ Am Geriatr Soc 2003;51:1252-9.

35. Donabedian A. The quality of care. How can it be assessed? JAMA 1988:260:1743-8

36. Mor V, Wool M, Guadagnoli E, et al. The impact of short-term case management on cancer patients' concrete needs and quality of life. Adv Med Sociol 1995;6:269.

37. Ritz LJ, Nissen MJ, Swenson KK, et al. Effects of advanced nursing care on quality of life and cost outcomes of women diagnosed with breast cancer. Oncol Nurs Forum 2000;27:923-32.

38. Uwer L, Rotonda C, Guillemin F, et al. Responsiveness of EORTC QLQ-C30, QLQ-CR38 and FACT-C quality of life questionnaires in patients with colorectal cancer. Health Qual Life Outcomes 2011:9:70 